\title{
Identification of AFLP markers linked to $M s$, a genic multiple allele inherited male-sterile gene in Chinese cabbage
}

\author{
Peng Wei, Hui Feng*, Zhongyun Piao, Chengyu Li, Zhiyong Liu, Yugang Wang, Ruiqin Ji, Ting Zou \\ and Shujuan Ji
}

Department of Horticulture, Shenyang Agricultural University, Shenyang, 110161, China

\begin{abstract}
As a first step toward cloning the genic multiple allele inherited male-sterile gene $M s$ in Chinese cabbage (Brassica rapa L. ssp pekinensis (Lour.) Olsson), we attempted the molecular tagging of this male-sterility locus using the amplified fragment length polymorphism (AFLP) technique. $\mathrm{A} \mathrm{BC}_{1}$ mapping population (130 plants) segregating for male sterility/fertility was constructed for the tagging using the bulked segregant analysis (BSA) method. Screening 144 primer combinations, four AFLP markers were identified to be tightly linked to the Ms gene, the nearest one of which, AFLP01, was converted to a SCAR marker for the markerassisted selection (MAS). Finally, a genetic map of the Ms gene was constructed with four AFLP markers and one SCAR marker, covering a total interval of $13.9 \mathrm{cM}$. Two markers AFLP01(SCAR01) and AFLP04 flanked the $M s$ locus at distances of 2.3 and $7.8 \mathrm{cM}$, respectively.
\end{abstract}

Key Words: Chinese cabbage, multiple allele inheritance, genic male sterility, AFLP, SCAR.

\section{Introduction}

Chinese cabbage (Brassica rapa L. ssp pekinensis (Lour.) Olsson) which originated in China is an important vegetable crop in extratropical, subtropical and tropical regions of the world. It is a diploid species with $2 \mathrm{n}=20$ chromosomes, and has a haploid genome size of about $550 \mathrm{Mbp}$ (Arumuganathan and Earle 1991). It is a typical crosspollinated plant with hermaphroditic flowers and obvious heterosis.

Male-sterile lines are ideal for the cross-breeding of Chinese cabbage. Male-sterile materials in Chinese cabbage can be classified into genic male sterility (GMS) and cytoplasmic male sterility (CMS) (Van der Meer 1987, Michael 2004). Most CMS lines in Chinese cabbage were bred from Ogu or Polima CMS source (Zhang et al. 2006). The male sterile lines with the Ogu CMS source cannot be used in the hybrid seed production for some defects, such as the leaf etiolation and the nectary degeneration (Ren and Cao 1992). On the other hand, those which were bred from the Polima CMS source have been used in hybrid seed production in China, but the thermal-sensitive sterility limited its performance in the large scale production (Zhang et al. 2001).

Compared to CMS, GMS in Chinese cabbage has more obvious advantages, such as stable and complete sterility performance, extensive distribution of restorers, and no negative cytoplasmic effects. Genic male sterility in Chinese cabbage was mostly considered as being controlled by a

Communicated by $\mathrm{T}$. Terachi

Received January 27, 2009. Accepted August 18, 2009.

*Corresponding author (e-mail: fenghuiaaa@263.net) monogenic recessive gene or a dominant gene. If a testcross is employed during the selection of maintaining lines of the male sterility, the percentage of male sterile plants in these lines only reaches $50 \%$. A pronounced drawback to using such male-sterile resources is the required manual removal of the fertile plants from the female parent line in seed production stage.

Feng et al. (1995) obtained four stable hereditary lines of Chinese cabbage comprising $100 \%$ male sterile plants by crossing male sterile plants with male fertile plants between AB lines. Later, a classical genetic analysis was designed and carried out to reveal the mechanism of inheritance of the male-sterility locus, and a genetic hypothesis of a genic multiple allele male-sterile gene was proposed (Feng et al. 1996). This hypothesis could satisfactorily explain most of our data. This model proposes the existence of a single locus with three alleles, the " $M s$ " allele for male sterility, the " $m s$ " allele for fertility, and the " $M s^{f}$ " for fertility restoration. The dominant-recessive $>$ relationship among these alleles was proposed to be $M s^{f}>M s>m s$. According to this genetic model, in order to obtain a male sterile line with $100 \%$ male sterile plants $(M s m s)$, a temporary maintainer line $(m s m s)$ is crossed with the homozygous sterile line (MsMs) (Fig. 1). Hybrid seed production could be subsequently carried out by using this population as the female parent. Thus, the manual removal of fertile plants in the sterile line, a necessary step in a two-line system, could be obviated.

Following this model, the male-sterile allele could be easily transferred into normal fertile lines. Thus, this allele could be used to breed new male-sterile lines in Chinese cabbage. This model may also be used to guide the research on male sterility in other crops, such as rape (Song et al. 2006). 


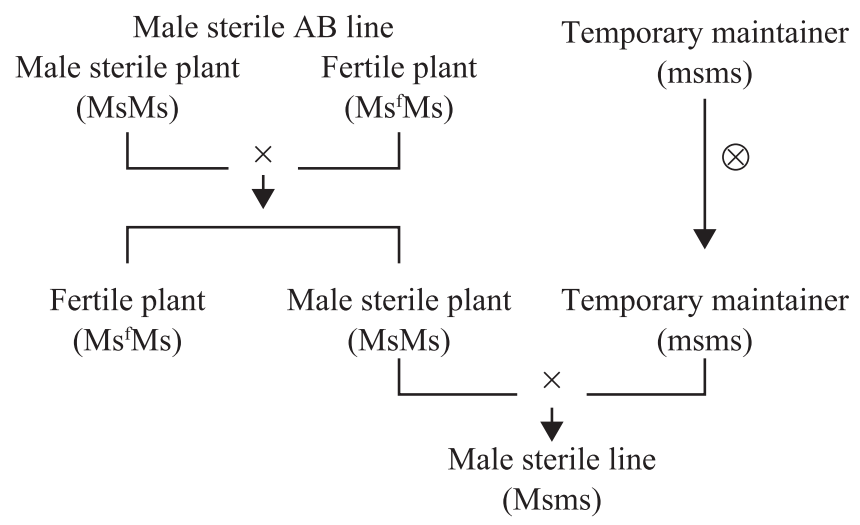

Fig. 1. Genetic model of genetic multiple allele male sterile line in Chinese cabbage

The model proposed by Feng et al. (1996) has been shown to be practical for hybrid seed production. The allele has been transferred to Chinese cabbage of different ecotypes (Wang et al. 2005, Feng et al. 2007). Some high quality male-sterile lines have been bred successfully. With these male-sterile materials, two commercial hybrids have been registered and released in China.

Molecular marker techniques have been widely used in genetic mapping, map-based cloning, genetic diversity analysis, variety protection, and breeding selection. Some studies of the male sterility in Brassica crops have been published. Various molecular markers that are linked to the restorer genes for Ogu, Pol and Tour CMS in Brassica have been identified (Hansen et al. 1997, Jean et al. 1997, 1998, Janeja et al. 2003). Miao et al. (2003) identified four sequence-tagged site (STS) markers that are tightly linked to a recessive male-sterile gene in Chinese cabbage; A group of homologs of the male-sterility or fertility gene have been isolated, and the relevant biological functions have been revealed (Wang et al. 2005, Cao et al. 2006, Jiang and Cao 2007, Li et al. 2008, Tian et al. 2009); Zhang et al. (2008) identified a random amplified polymorphic DNA (RAPD) marker that is tightly linked to a dominant male sterile gene and converted it into a sequence characterized amplified region (SCAR) marker. Wang et al. (2000), Ke et al. (2005), Yi et al. (2006), Hong et al. (2006), Lei et al. (2007) and Huang et al. (2007) identified a set of molecular markers that are linked to the male sterile gene in Brassica napus. Wang et al. (2000a, 2000b) identified 12 amplified fragment length polymorphism (AFLP) markers, a SCAR marker and an extended random primer amplified region (ERPAR) marker that are closely linked to a dominant male-sterile gene in Brassica oleracea, and mapped the gene to linkage group 09 , corresponding to chromosome 3 of $B$. oleracea.

The "Multiple-allele model" of male sterility created a new way to use the genic male-sterile materials in Chinese cabbage; however, the special inheritance model of this locus results in six total genotypes, four of which present identical fertile phenotypes, while the other two are sterile. Traditionally, it takes more work and time to determine the desired genotype through a testcross. Marker-assisted selection is an efficient way to solve the problem, though tightlylinked and easily-detected molecular markers are needed for this type of analysis.

In the present study, we focused on constructing an AFLP genetic map of the $M s$ gene. The application of one converted SCAR marker to MAS is also discussed.

\section{Materials and Methods}

Plant materials and development of the mapping population The AB01-1 is a male sterile plant of a previously bred AB line of Chinese cabbage (Brassica rapa L. ssp. pekinensis (Lour.) Olsson) with sterile plants (AB01-1, MsMs) and fertile plants (AB01-2, $\left.M s^{f} M s\right)$ segregated in a ratio of $1: 1$. It is a complete and stable male-sterile plant, with withered anthers and a normal pistil, which was employed as the female parent of the mapping population. The male parent was SD2 (msms), a fertile inbred line in Chinese cabbage.

$\mathrm{A} \mathrm{BC}_{1}$ population was constructed to tag the genic multiple allele inherited male-sterile locus. A plant of AB01-1 was crossed to SD2, resulting in a $F_{1}$ population with $100 \%$ male-sterile plants. A segregating population was obtained by backcrossing a sterile $\mathrm{F}_{1}$ plant with SD2. The sterility was determined during flowering.

\section{DNA extraction and preparation of bulks}

Genomic DNA was isolated from fresh leaves of parents and $\mathrm{BC}_{1}$ plants following the procedure of Pierre and Marechal-Drouard (1992) with minor modifications. Grind $1.5 \mathrm{~g}$ of the sample in liquid nitrogen, then transfer the sample into a centrifuge tube containing $10 \mathrm{ml}$ of extraction medium (100 mM sodium acetate, $50 \mathrm{mM}$ EDTA, $500 \mathrm{mM} \mathrm{NaCl}, 2 \%$ soluble PVP, $20 \mathrm{mM}$ cysteine, and $1.4 \% \mathrm{SDS}$ ) and incubate at $65^{\circ} \mathrm{C}$ for $30 \mathrm{~min}$; add $5 \mathrm{ml}$ of potassium acetate $(5 \mathrm{M}, \mathrm{pH}=$ 4.8 ) and incubate on ice for $30 \mathrm{~min}$; centrifuge at $10,000 \mathrm{~g}$ at $4^{\circ} \mathrm{C}$ for $10 \mathrm{~min}$; decant the supernatant into another centrifuge tube; add 0.6 vol. isopropanol and incubate at $-20^{\circ} \mathrm{C}$ for $20 \mathrm{~min}$; centrifuge at $10,000 \mathrm{~g}$ at $4^{\circ} \mathrm{C}$ for $10 \mathrm{~min}$; pour off the supernatant, add $25 \mathrm{ml}$ of $100 \%$ ethanol, and wash for one h; centrifuge at $10,000 \mathrm{~g}$ at $4{ }^{\circ} \mathrm{C}$ for five min; pour off the ethanol and pre-dissolve DNA pellet in $500 \mu \mathrm{l}$ of water; add $50 \mu \mathrm{g}$ of RNase $(10 \mathrm{mg} / \mathrm{ml})$ and incubate at $37^{\circ} \mathrm{C}$ for $30 \mathrm{~min}$; add $50 \mu \mathrm{l}$ of $\mathrm{NaAc}(3 \mathrm{M})$ and $500 \mu \mathrm{l}$ of isopropanol; centrifuge at $10,000 \mathrm{~g}$ at $4^{\circ} \mathrm{C}$ for $15 \mathrm{~min}$; wash with $70 \%(\mathrm{v} / \mathrm{v})$ ethanol and air dry for $5 \mathrm{~min}$; redissolve DNA pellet in $50 \mu \mathrm{l}$ of $\mathrm{ddH}_{2} \mathrm{O}$.

A spectrophotometer was used to quantify DNA quantification. Fertile and sterile bulks were prepared for BSA (bulked segregant analysis) by pooling equal quantities of DNA from ten fertile $(m s m s)$ and ten sterile $(M s m s)$ individuals.

\section{AFLP analysis}

AFLP analysis was performed using the method described by Vos et al. (1995) with minor modifications. One hundred and forty four primer combinations were tested for 
polymorphism analysis between the bulks. Genomic DNA (500 ng) was digested for $1 \mathrm{~h}$ at $37^{\circ} \mathrm{C}$ in a total volume of $25 \mu \mathrm{l}$ (5 U PstI, $5 \mathrm{U}$ Mse I, $10 \mathrm{mM}$ Tris-HAc, $10 \mathrm{mM} \mathrm{MgAc}$, $50 \mathrm{mM}$ KAc, $5 \mathrm{mM}$ DTT, $50 \mathrm{ng} / \mu \mathrm{l} \mathrm{BSA}$ ). After heatinactivation of restriction enzymes at $75^{\circ} \mathrm{C}$ for $15 \mathrm{~min}, 25 \mu \mathrm{l}$ of a solution containing 5 pmol Pst $\mathrm{I}$-adapters, 50 pmol Mse I-adapters, $1 \mathrm{U}$ T4 DNA-ligase, $1 \mathrm{mM}$ ATP in $10 \mathrm{mM}$ Tris-HAc, $10 \mathrm{mM} \mathrm{MgAc}, 50 \mathrm{mM}$ KAc, $5 \mathrm{mM}$ DTT, $50 \mathrm{ng} / \mu \mathrm{l}$ BSA was added and incubated at $37^{\circ} \mathrm{C}$ for $3 \mathrm{~h}$. A $5-\mu \mathrm{l}$ aliquot of a tenfold dilution of the restriction/ligation mixture was pre-amplified with primers complementary to the adaptor sequence and including one additional selective nucleotide at the $3^{\prime}$ end of an PstI directed primer $(\mathrm{P}+\mathrm{G})$ and an Mse I directed primer $(\mathrm{M}+\mathrm{C})$. Pre-amplification reaction contained $0.2 \mathrm{mM}$ dNTP, $1 \times$ PCR buffer $(20 \mathrm{mM}$ Tris- $\mathrm{HCl}(\mathrm{pH} 8.4)$; $\left.20 \mathrm{mM} \mathrm{KCl} ; 10 \mathrm{mM}\left(\mathrm{NH}_{4}\right)_{2} \mathrm{SO}_{4} ; 1.5 \mathrm{mM} \mathrm{MgCl}_{2}\right), 27 \mathrm{ng}$ each of Pst $\mathrm{I}+\mathrm{G} / \mathrm{Mse} \mathrm{I}+\mathrm{C}$, and $1 \mathrm{U}$ of Taq DNA polymerase. The sequences of adaptors and pre-amplification primers are presented in Table 1 . The amplicon was diluted 50-fold and used as template DNA in selective amplification reactions, which were carried out using with two primers additional selective nucleotides at the $3^{\prime}$ end for all the enzyme digests. To identify markers, 144 primer combinations were made with the $12 P s t \mathrm{I}+\mathrm{GNN}$ and $12 \mathrm{Mse} \mathrm{I}+\mathrm{CNN}$ primers (Table 2). Selective PCR was performed with the aforementioned $1 \times$ PCR buffer, $0.2 \mathrm{mM}$ dNTP, $30 \mathrm{ng} M s e \mathrm{I}+\mathrm{CNN}, 15$ ng Pst $\mathrm{I}+\mathrm{GNN}$, and $0.4 \mathrm{U}$ of Taq DNA polymerase. All amplifications were performed in a BIO-RAD iCycler with the PCR conditions described by Vos et al. (1995). PCR products were mixed with an equal volume of loading dye $(98 \%$ formamide, $10 \mathrm{mM}$ EDTA, $0.001 \%$ each of xylene cyanol and bromphenol blue). Samples were denatured at $94^{\circ} \mathrm{C}$ for 5 min and separated on a $6 \%$ denaturing polyacrylamide gel at $85 \mathrm{~W}$. After electrophoresis, the gel was developed using a silver staining kit (Bioneer, Daejeon, Korea).

\section{Conversion of AFLP markers to SCAR markers}

Gel pieces containing the AFLP markers were sliced and boiled for $5 \mathrm{~min}$ in $100 \mu \mathrm{l}$ of sterile water. After centrifugation, a $5-\mu 1$ aliquot of the supernatant was amplified with the corresponding selective primer combination and the same PCR conditions that were used in the selective amplification. The amplicons were separated on a 1.0\% agarose gel, then eluted with a gel extraction kit (Tiangen, Beijing, China). The eluted AFLP fragments were cloned into the pGEM-T Easy Vector system I (Promega, USA). The AFLP clones were sequenced from both ends using an ABI PRISM 377 automated sequencer. Primer pairs for developing SCAR markers were designed based on the two terminal sequences using the Primer3 program (Rozen and Skaletsky 1996). PCR conditions were optimized with the preamplification products of the two parents and the two bulks as templates. Subsequently, these conditions were used to amplify genomic DNA from the $20 \mathrm{BC}_{1}$ plants that constituted the two bulks. PCR products were separated on a $2 \%$ agarose gel and a $6 \%$ denaturing polyacrylamide gel. SCAR
Table 1. Sequences of adapters and primers that were used in the AFLP analysis

\begin{tabular}{llr}
\hline \hline Enzyme & Adapter sequence $\left(5^{\prime}>3^{\prime}\right)$ & $\begin{array}{r}\text { Pre-amplification } \\
\text { primers }\left(5^{\prime}>3^{\prime}\right)\end{array}$ \\
\hline PstI & $\begin{array}{l}\text { Oligo } 1 \text { ctcgtagactgcgtacatgca } \\
\text { Oligo 2 catctgacgeatgt }\end{array}$ & gactgcgtacatgcag \\
MseI & $\begin{array}{l}\text { Oligo 1 gacgatgagtcctgag } \\
\text { Oligo 2 tactcaggactcat }\end{array}$ & gatgagtcctgagtaac \\
&
\end{tabular}

Table 2. Sequences of selective-amplification primers used in the AFLP analysis

\begin{tabular}{lcccccccccccc}
\hline \hline & 1 & 2 & 3 & 4 & 5 & 6 & 7 & 8 & 9 & 10 & 11 & 12 \\
\hline $\mathrm{P}+$ & $\mathrm{ca}$ & $\mathrm{cg}$ & $\mathrm{ct}$ & $\mathrm{ga}$ & $\mathrm{gc}$ & $\mathrm{gt}$ & $\mathrm{ta}$ & $\mathrm{tg}$ & $\mathrm{tt}$ & $\mathrm{ac}$ & at & ag \\
$\mathrm{M}+$ & $\mathrm{ca}$ & $\mathrm{cg}$ & $\mathrm{ct}$ & $\mathrm{ga}$ & $\mathrm{gc}$ & $\mathrm{gt}$ & ta & tg & tt & ac & at & ag
\end{tabular}

P: pre-amplification primer for PstI; M: pre-amplification primer for MseI

markers were considered successful when a fragment was amplified with the primer pairs and showed polymorphism between fertile and sterile plants under the optimized condition in the AFLP marker analysis.

\section{Linkage analysis}

Linkage analysis of markers and traits was carried out using MAPMAKER version 3.0 (Lander et al. 1987). A genetic map was constructed based on a minimum LOD score of 3 and a maximum recombination fraction of 0.4 . Map distances in centimorgans (cM) were calculated using the Kosambi mapping function (Kosambi 1944).

\section{Results}

\section{Phenotyping of male fertility and sterility}

To tag the male sterile gene, a $\mathrm{BC}_{1}$ population was used. Only two phenotypes, male sterile and fertile, were observed. Male sterile and fertile plants could be distinguished unambiguously via visual examination. The $\mathrm{BC}_{1}$ population (130 plants) segregated for male sterility (61) and fertility (69) according to the expected $1: 1$ ratio for monogenic inheritance.

\section{AFLP analysis}

To identify markers linked to the $M s$ gene, AFLP analysis was carried out with BSA. We tested 144 Pst I/MseI primer combinations for DNA amplification polymorphism in the two bulks. The Pst $\mathrm{I}+\mathrm{GTA}$ primers did not yield a product when combined with any of the $12 \mathrm{Mse}+\mathrm{CNN}$ primers. The remaining 132 primer combinations yielded approximately 40 bands per primer combination. The frequency of polymorphism between two parents was around $18 \%$, with a range of $2-30 \%$. Of the 1,590 polymorphic loci detected between the two parents, 10 displayed polymorphism with respect to the two bulks, in which four were shown in Fig. 2. The size of the amplified fragments ranged from 50 to 800 bases. Primer 
combinations yielding polymorphic amplification patterns between the bulks were further examined in individual $\mathrm{BC}_{1}$ plants that were used to prepare the bulks. A total of 40 individuals (20 of each type) were examined. Four primer combinations gave polymorphic amplification patterns in individual plants; the sizes of the polymorphic amplicons ranged between 154 and $380 \mathrm{bp}$.

\section{Conversion of AFLP markers into SCAR markers}

The polymorphic fragments were eluted from the gel, reamplified with the respective primers, ligated with a cloning vector, and transformed into E. coli. The polymorphic AFLP markers were cloned and sequenced. The sequences were subjected to BLAST analysis. None of them showed significant homology in the BLAST results.

Based on sequence of the AFLP clones, SCAR primers were designed for PCR amplification. Only AFLP01 was successfully converted into a SCAR marker, which was subsequently named SCAR01 (Table 3 ). SCAR01 primers gave one amplicon of $255 \mathrm{bp}$ in PCR. This band was present almost exclusively in sterile individuals and absent in fertile individuals (Fig. 3). When $130 \mathrm{BC}_{1}$ individuals were tested with the SCAR primers, the amplicon was obtained in 59 sterile plants; only one out of the 69 fertile plants produced the amplicon. As such, a strong association was found between the SCAR01 marker and the male sterility.

\section{Linkage analysis}

In the present study, a total of $130 \mathrm{BC}_{1}$ plants were screened with four AFLP markers and one SCAR marker. All of these markers were found to segregate normally within the mapping population (Table 4). The linkage map that

\section{AFLP01 AFLP02 AFLP03 AFLP04}

\section{Pf Bf Bs Ps Pf Bf Bs Ps Pf Bf Bs Ps Pf Bf Bs Ps}

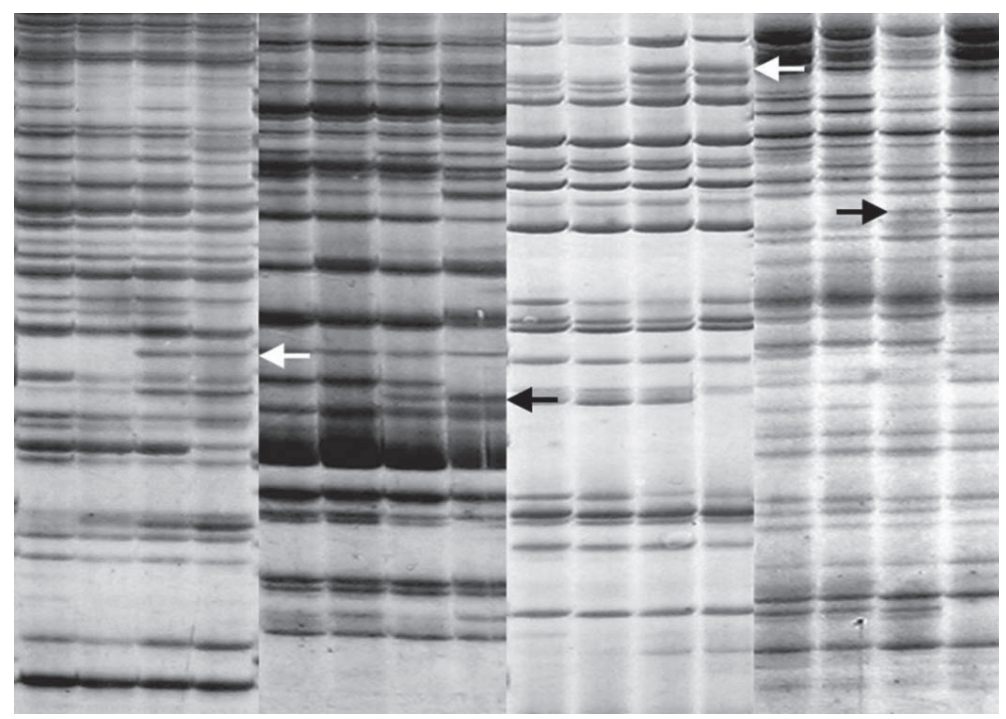

Fig. 2. AFLP profiles showing the polymorphic amplification patterns that were associated with the multiple allele inherited male sterility trait obtained with primer combinations AFLP01 Pggt/Mcac, AFLP02 Pggc/Mcct, AFLP03 Pgga/Mcgc, AFLP04 Pgca/Mctt. The position of polymorphic band is indicated with an arrow. Pf fertile parent, Ps male sterile parent, Bf fertile bulk, Bs male sterile bulk.

Table 3. Details of PCR conditions and SCAR primers for amplifying male sterility-specific AFLP markers

\begin{tabular}{lllcc}
\hline \hline Name & Acc. No. & Sequence of primer pairs $\left(5^{\prime}-3^{\prime}\right)$ & Size & Tm \\
\hline SCAR01 & FJ851467 & F:CACGGATCATCAGCTCCATGT; & $255 \mathrm{bp}$ & $58^{\circ} \mathrm{C}$ \\
& & R:GGTAGAAAACCAATCGAACCAAGA & \\
\hline
\end{tabular}

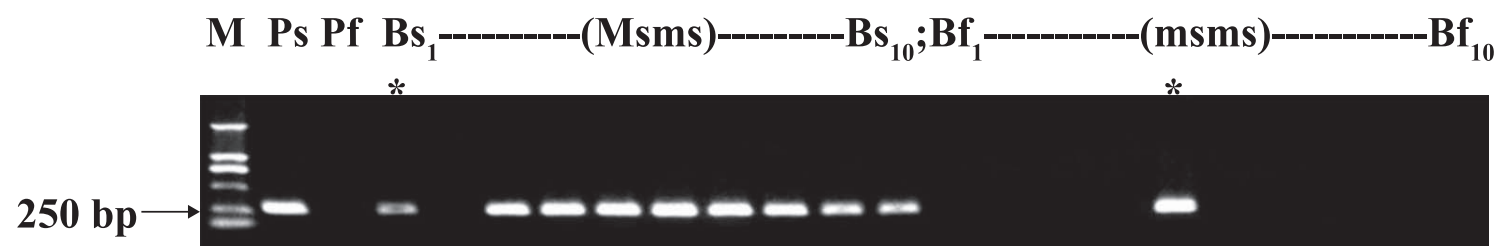

Fig. 3. Segregation of SCAR01 marker in $\mathrm{BC}_{1}$ individuals. M DL2000 DNA ladder, Ps male sterile parent, $\mathrm{Pf}$ fertile parent, $\mathrm{Bf}_{1}-\mathrm{Bf}_{10}$ ten fertile $\mathrm{BC}_{1}$ individuals, $\mathrm{Bs}_{1}-\mathrm{Bs}_{10}$ ten sterile $\mathrm{BC}_{1}$ individuals. Recombinants are indicated by asterisks. 
Table 4. Segregation of AFLP markers in the $\mathrm{BC}_{1}$ population

\begin{tabular}{|c|c|c|c|c|c|c|}
\hline \multirow[t]{2}{*}{ S.no. } & \multirow[t]{2}{*}{ Name } & \multirow{2}{*}{$\begin{array}{c}\text { Primer } \\
\text { combination }\end{array}$} & \multicolumn{2}{|c|}{$\begin{array}{l}\text { Segregation } \\
\text { pattern }\end{array}$} & \multirow{2}{*}{$\begin{array}{l}\text { Expected } \\
\text { ratio }\end{array}$} & \multirow{2}{*}{$\begin{array}{c}\chi^{2} \\
\left(\chi^{2} 0.05,1=3.84\right.\end{array}$} \\
\hline & & & Absent & Present & & \\
\hline 1 & AFLP01 & Pggt/Mcac & 70 & 60 & $1: 1$ & 0.623 \\
\hline 2 & AFLP02 & Pggc/ & 71 & 59 & $1: 1$ & 0.931 \\
\hline 3 & AFLP03 & Pgga/Mcgc & 69 & 61 & $1: 1$ & 0.377 \\
\hline 4 & AFLP04 & Pgca/Mctt & 69 & 61 & $1: 1$ & 0.377 \\
\hline
\end{tabular}

was constructed with these markers is presented in Fig. 4. Linkage analysis of the segregation data for these markers was performed with MAPMAKER version 3.0; our results indicate that all markers map to the same linkage group with a minimum LOD score of 3 . We could localize these markers and the $M s$ locus to an interval of $13.9 \mathrm{cM} . M s$ was found to be flanked by the AFLP01 (SCAR01) and AFLP04 markers at genetic distances of 2.3 and $7.8 \mathrm{cM}$, respectively.

\section{Discussion}

Since this genic multiple allele inherited male-sterile material has so many advantages, considerable attention has been paid to it. Based on the proposed inheritance model of multiple alleles, the breeding for a male sterile line with $100 \%$ male sterility and $100 \%$ male sterile plants is easy; it requires more time and space to select plants with desired genotypes, however, because a testcross must be involved at each generation. The identification of molecular markers that are closely linked to the $M s$ gene allows for a more efficient and earlier selection of the desired plants. For practical use, we sought to establish a tightly linked SCAR marker in this research.

Molecular markers tightly linked to genes that are responsible for traits of economic importance are valuable in marker-assisted selection breeding programs. The $M s-$ specific markers identified here should greatly enhance the selection efficiency in backcross breeding by using a PCRbased selection of plants carrying $M s$ in an early seedling stage. Though only one SCAR marker has been developed, only three recombinants were detected in $130 \mathrm{BC}_{1}$ plants; this result suggests that this SCAR marker can correctly predict the genotype in all but $2.3 \%$ of the samples. Furthermore, it can be easily detected on agarose gels. Therefore, this SCAR marker can be used in backcrosses to breed malesterile lines carrying an $M s$ gene.

Markers closely linked to specific traits can be easily identified by bulked segregant analysis (BSA) if an appropriate population is available. BSA, devised by Michelmore et al. (1991), has been the most powerful and widely employed method for the molecular tagging of traits. For tagging qualitative traits that can be easily classified into two or more discreet classes, BSA is particularly efficient. The advantage of this approach is that the likelihood of identifying false positive markers is very small (Michelmore et al. 1991,

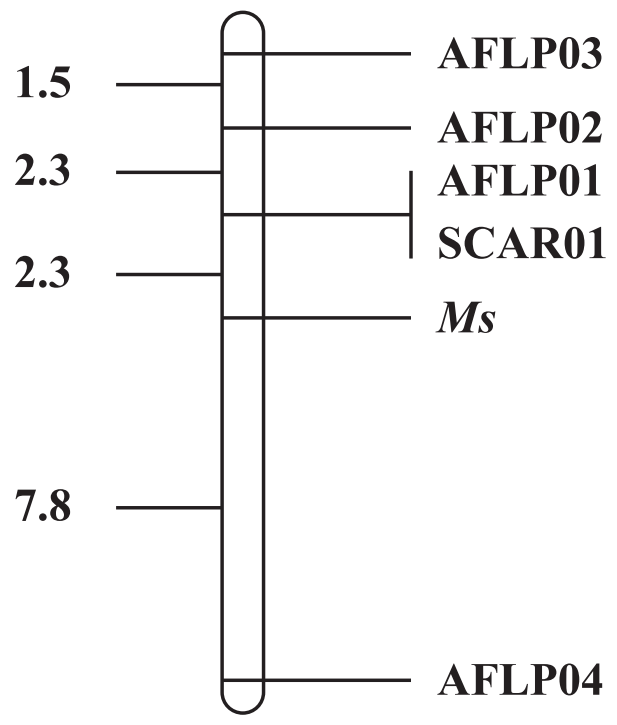

Fig. 4. Genetic linkage map of the $M s$ locus generated with the $\mathrm{BC}_{1}$ population of $\mathrm{AB} 01-1 / \mathrm{SD} 2$. The genetic distance in centimorgans $(\mathrm{cM})$ was calculated using the Kosambi mapping function.

Meksem et al. 1995, Li et al. 1998). The combination of the AFLP technique and BSA has been effectively used to generate molecular markers that are closely linked to the genes of interest in many crops (Chantret et al. 2000, Miftahudin et al. 2002, Asnaghi et al. 2004). In most of these studies, $\mathrm{F}_{2}$ populations were used to establish pools (Gallego et al. 1998), however, the dominant male-sterile gene results in a $\mathrm{F}_{1}$ population with $100 \%$ male-sterile plants. In the present case, we employed $\mathrm{BSA}$ and used $\mathrm{BC}_{1}$ plants to assemble DNA pools. We successfully identified four AFLP markers and one SCAR markers that are closely linked to the $M S$ gene in Chinese cabbage.

Although AFLP markers are very useful for linkage mapping, the generation of these markers is often expensive and labor intensive. Therefore, these markers cannot be conveniently used for large-scale marker-assisted plant breeding. For practical purposes, these markers need to be converted to SCAR markers. SCAR markers are an ideal choice for MAS, because they are detected by single genetically defined loci, are identified as distinct bands in agarose gels, are easier to score, are less sensitive to reaction conditions, and are more reproducible. Many successful cases of such conversions have been reported (Shan et al. 1999, Negi et al. 2000, Miftahudin et al. 2002). Not all AFLP markers can be successfully converted, however, perhaps because undesired AFLP fragments contaminate the isolation of true fragments from gels. As demonstrated by Xu et al. (2001), the following factors probably cause this contamination. First, there is a difference in mobility between the visible, single ${ }^{33}$ P-labelled-DNA strand and its invisible, complementary DNA strand (Vos et al. 1995); thus it is possible that other invisible AFLP bands can contaminate the isolation of a desired AFLP marker. Second, the presence of neighboring AFLP fragments may allow for contamination. In the 
present study, we used the silver staining to visualize AFLP fragments. We believe that the most likely reason for contamination in the present study is neighboring AFLP fragments.

As the first step towards the map-based cloning of the $M s$ gene, we identified markers flanking the $M s$ gene: AFLP01 (SCAR01) and AFLP04 at a 10.1 cM interval on the genetic linkage map. These two tightly flanking markers will be useful as starting points for gene isolation and cloning (Tanksley et al. 1989).

\section{Acknowledgment}

This research was supported by grants from the National Natural Science Foundation of China (No. 30671414) and National "863" Plan Program (No. 2006AA10Z170) of PR China.

\section{Literature Cited}

Arumuganathan, K. and E.D.Earle (1991) Nuclear DNA content of some important plant species. Plant Mol. Biol. Reptr. 9: 211-215.

Asnaghi,C., D.Roques, S.Ruffel, C.Kaye, J.Y.Hoarau, H.Télismart, J.C.Girard, L.M.Raboin, A.M.Risterucci, L.Grivet and A.D'Hont (2004) Targeted mapping of a sugarcane rust resistance gene (Brul) using bulked segregant analysis and AFLP markers. Theor. Appl. Genet. 108: 759-764.

Cao,J.S., X.L.Yu, W.Z.Ye, G.Lu and X.Xiang (2006) Functional analysis of a novel male fertility CYP86MF gene in Chinese cabbage (Brassica compestris L. ssp. Chinensis makino). Plant Cell Rep. 24: 715-723.

Chantret,N., P. Sourdille, M. Röder, M.Tavaud，M.Bernard and G.Doussinault (2000) Location and mapping of the powdery mildew resistance gene MIRE and detection of a resistance QTL by bulked segregant analysis (BSA) with microsatellites in wheat. Theor. Appl. Genet. 100: 1217-1224.

Feng,H., Y.T.Wei and S.N.Zhang (1995) Inheritance of and utilization model for genic male sterility in Chinese cabbage (Brassica pekinensis Rupr.). Acta Horticulturae 402: 133-140.

Feng,H., Y.T.Wei, S.J.Ji, G.Jin, J.S.Jin and W.J.Dong (1996) Multiple allele model for genic male sterility in Chinese cabbage. Acta Horticulturae. 467: 133-142.

Feng,H., W.Xu and Y.G.Wang (2007) Directive transfer of the genetic male sterile line of milk Chinese cabbage AI023. Acta Horticulturae Sinica 34: 659-664.

Gallego,F.J., B.Calles and C.Benito (1998) Molecular markers linked to the aluminium tolerance gene Alt1 in rye (Secale cereale L.). Theor. Appl. Genet. 97: 1104-1109.

Hansen,M., C.Hallden, N.Nilsson and T.Sall (1997) Marker-assisted selection of restored male-fertile Brassica napus plants using a set of dominant RAPD markers. Mol. Breeding 3: 449-456.

Hong,D.F., L.L.Wan, P.W.Liu, G.S.Yang and Q.B.He (2006) AFLP and SCAR markers linked to the suppressor gene $(R f)$ of a dominant genetic male sterility in rapeseed (Brassica napus L.). Euphytica 151: 401-409.

Huang,Z., Y.F.Chen, B.Yi, L.Xiao, C.Z.Ma, J.X.Tu and T.D.Fu (2007) Fine mapping of the recessive genic male sterility gene (Bnms3) in Brassica napus L. Theor. Appl. Genet. 115: 113-118.

Janeja,H.S., S.S.Banga and M.Lakshmikumaran (2003) Identification of AFLP markers linked to fertility restorer genes for tournefortii cytoplasmic male-sterility system in Brassica napus. Theor. Appl. Genet. 107: 148-154.

Jean, M., G.G.Brown and B.S.Landry (1997) Genetic mapping of nuclear fertility restorer genes for the 'Polima' cytoplasmic male sterility in canola (Brassica napus L.) using DNA markers. Theor. Appl. Genet. 95: 321-328.

Jean, M., G.G.Brown and B.S.Landry (1998) Targeted mapping approaches to identify DNA markers for the 'Polima' CMS of canola (Brassica napus L). Theor. Appl. Genet. 97: 431-438.

Jiang,M. and J.S.Cao (2007) Isolation and characterization of a male sterility gene homolog $B c M S 2$ from Chinese cabbage-pak-choi that expressing in an anther-specific manner. Mol. Biol. Rep. 35: 299305 .

Ke,L.P., Y.Q.Sun, D.F.Hong, P.W.Liu and G.S.Yang (2005) Identification of AFLP markers linked to one recessive genic male sterility gene in oilseed rape, Brassica napus. Plant Breed. 124: 367-370.

Kosambi,D.D. (1944) The estimation of map distance from recombination values. Ann. Eugen. 12: 172-175.

Lander,E.S., P.Green, J.Abrahamson, A. Barlow, M.J.Daly, S.E. Lincoln and L.Newburg (1987) Mapmaker: an interactive computer package for constructing primary genetic linkage maps of experimental and natural populations. Genomics 1: 174-181.

Lei, S.L., X.Q.Yao, B.Yi, W.Chen, C.Z.Ma, J.X.Tu and T.D.Fu (2007) Toward map-based cloning: fine mapping of a recessive genic male-sterile gene (BnMs2) in Brassica napus L. and syntenic region identification based on the Arabidopsis thaliana genome sequences. Theor. Appl. Genet. 115: 643-651.

Li, X., H.J. Van Eck, J.N.A.M. Rouppe Van der Voort, D.J. Huigen, P.Stam and E. Jacobsen (1998) Autotetraploids and genetic mapping using common AFLP markers: the $R 2$ allele conferring resistance to Phytophthora infestans mapped on potato chromosome 4. Theor. Appl. Genet. 96: 1121-1128.

Li,Y.Y., J.S.Cao, H.Li, X.L.Yu and X.Xiang (2008) BcMF13, a new reproductive organ-specific gene from Brassica rapa. ssp. chinensis, affects pollen development. Mol. Biol. Rep. 35: 207-214.

Meksem, K., D. Leister, J. Peleman, M.Zabeau, F. Salamini and C.Gebhardt (1995) A high-resolution map of the vicinity of the R1 locus on chromosome $\mathrm{V}$ of potato based on RFLP and AFLP markers. Mol. Gen. Genet. 249: 74-81.

Miao, Y., F.Dreyer, D.G.Cai and C.Jung (2003) Molecular markers for genic male sterility in Chinese cabbage. Euphytica 132: 227-234.

Michael,J.H. (2004) The use of cytoplasmic male sterility for hybrid seed production. Molecular Biology and Biotechnology of Plant Organelles. Springer, Netherlands, pp. 623-634.

Michelmore,R.W., I.Paran and R.V.Kesseli (1991) Identification of markers linked to disease-resistance genes by bulked segregant analysis: a rapid method to detect markers in specific genomic regions by using segregating populations. Proc. Natl. Acad. Sci. 88: 9828-9832.

Miftahudin, G.J., J.P.Scoles and J.P.Gustafson (2002) AFLP markers tightly linked to the aluminum-tolerance gene Alt3 in rye (Secale cereale L.). Theor. Appl. Genet. 104: 626-631.

Negi, M.S., M.Devic, M.Delseny and M.Lakshmikumaran (2000) Identification of AFLP fragments linked to seed coat color in Brassica juncea and conversion to a SCAR marker for rapid selection. Theor. Appl. Genet. 101: 146-152.

Pierre, G. and L.Marechal-Drouard (1992) Isolation of plant DNA: A fast, inexpensive and reliable method. Plant Mol. Biol. Rep. 10: $60-65$.

Rozen, S. and H.J.Skaletsky (1996) Primer3: a software component 
for picking PCR primer. Source code available at http://www. genome.wi.mit.edu/genome_software/other/primer3.html.

Ren,C.W. and S.C.Cao (1992) A survey of some physiological characteristics related to the yellowing defect in cytoplasmic male sterile Brassica campestris ssp.chinensis with r-cms cytoplasm. Acta Horticulturae Sinica 19: 275-276.

Shan, X., T.K. Blake and L.E.Talbert (1999) Conversion of AFLP markers to sequence-specific PCR markers in barley and wheat. Theor. Appl. Genet. 98: 1072-1078.

Song,L.Q., T.D.Fu, J.X.Tu, C.Z.Ma and G.S.Yang (2006) Molecular validation of multiple allele inheritance for dominant genic male sterility gene in Brassica napus L. Theor. Appl. Genet. 113: 55-62.

Tanksley, S.D., N.D. Youmg, A.H.Paterson and M.W.Bonierbale (1989) RFLP mapping in plant breeding: new tools for an old science. Biotechnology 7: 257-264.

Tian,A.M., J.S.Cao, H.Li, X.L.Yu and W.Z.Ye (2009) Characterization of a male sterile related gene BcMF15 from Brassica campestris ssp. chinensis. Mol Biol Rep. 36: 307-314.

Van der Meer,Q.P. (1987) Chromosomal monogenic dominant male sterility in Chinese Cabbage (Brassica rapa Subsp. Pekinensis (Lour.) Hanelt). Euphytica 36: 927-931.

Vos,P., R.Hogers, M.Bleeker, M.Reijans, T.VandeLee, M.Hornes, A.Frijters, J.Pot, J.Peleman, M.Kuiper and M.Zabeau (1995) AFLP: a new technique for DNA fingerprinting. Nucleic Acids Res. 23: 4407-4414.

Wang, J.X., G.S. Yang, T.D.Fu and J.L.Meng (2000) Development of PCR-based markers linked to the fertility restorer gene for the polima cytoplasmic male sterility in rapeseed (Brassica napus L.). Acta Genetica Sinica 27: 1012-1017.

Wang,L.P., J.S.Cao, M.Z.Ye, X.Xiang and X.L.Yu (2005) Cloing and identification of CYP86MF homologous genes from Cruciferae. Journal of Agricultural Biotechnology 13: 145-151.
Wang,X.W., Z.Y.Fang, P.T.Sun, Y.M.Liu, L.M.Yang and M.Zhuang (2000a) A SCAR marker applicable in marker assisted selection of a dominant male sterility gene in cabbage. Acta Horticlturae Sinica 27: 143-144.

Wang,X.W., Z.Y.Fang, S.W.Huang, P.T.Sun, Y.M.Liu, L.M.Yang, M.Zhuang and D.Y.Qu (2000b) An extended random primer amplified region (ERPAR) marker linked to a dominant male sterility gene in cabbage (Brassica oleracea var. capitata). Euphytica 112: 267-273.

Wang,Y.G., H.Feng, G.R.Lin, S.F.Xu, K.Y.Yang and N.J.Zhang (2005) The Transfer of genetic male sterile lines in Brassica campestris L. ssp. chinesis (L.) Makino. Acta Horticulturae Sinica. 32: 628-631.

Xu,M.L., E.Huaracha and S.S.Korban (2001) Development of sequence characterized amplified region (SCARs) from amplified fragment length polymorphism (AFLP) markers tightly linked to the $V f$ gene in apple. Genome 44: 63-70.

Yi,B., Y.N.Chen, S.L.Lei, J.X.Tu and T.D.Fu (2006) Fine mapping of the recessive genic male-sterile gene (Bnms1) in Brassica napus L. Theor. Appl. Genet. 113: 643-650.

Zhang,D.S., F.L.Zhang, Y.J.Wang, Z.Y.Fang, Y.J.Yu, X.Y.Zhao and J.B.Xu (2006) Molecular identification of cytoplasmic male sterile line CMS96 in Chinese cabbage. Molecular Plant Breeding 4: 545552 .

Zhang,L.G., D.F.Hao and G.L.Ke (2001) Characteristics of sterility in CMS 3411-7 of Chinese cabbage sensitive to low temperature. Acta Horticulturae Sinica 28: 415-420.

Zhang, S.J., F.Li, H.P.Han, S.F.Zhang, X.G.Niu and R.F.Sun (2008) Molecular marker linked to a dominant genetic male sterile gene in Chinese cabbage. [Brassica rapa L. ssp. pekinensis (Lour.) Olsson]. Scientia Agricultura Sinica 41: 2379-2385. 